\title{
Neuromarketing: Understanding Customers' Subconscious Responses to Marketing
}

\author{
Jyrki Suomala, Lauri Palokangas, Seppo Leminen, \\ Mika Westerlund, Jarmo Heinonen, and Jussi Numminen
}

\author{
"Executives love the idea of using brain scans. As brain" \\ imaging and neuroscience develop, neuromarketing \\ companies will be able to pull out more sophisticated data \\ about what makes people want to buy or avoid certain \\ items. The big question is whether neuromarketing can \\ push a 'buy button' in your brain.
}

Nick Lee

Professor of Marketing Aston University

\begin{abstract}
This article presents neuromarketing as a way to detect brain activation during customer engagement. Neuromarketing is a field of marketing research that studies consumers' sensorimotor, cognitive, and affective response to marketing stimuli. We established a Virtual Customer Journey model based on the consultative selling process to study customer engagement by using brain scans. Consultative selling suggests that a customer's shopping experience is managed by the salesperson's behaviour and in-store marketing assets, and that the customer gets engaged step by step. A total of 16 test subjects were shown video clips and still pictures from a consultative sales process at Nokia's flagship stores, and their brain activity was scanned. The results show that test subjects were able to associate themselves with people and events on the video and they felt safe and comfortable during the consultative selling process. The study implies that laboratories can build virtual environments that resemble real shopping environments where customers can participate in the buying process and respond to events displayed on the screen, and that neuroimaging is useful in providing valuable information on customer behaviour that is not achievable otherwise.
\end{abstract}

\section{Introduction}

Whereas traditional marketing has concentrated on the value and competitive advantages of a product or service, contemporary marketing takes a holistic approach by also considering the purchasing process and the retail store atmosphere to evoke a positive shopping experience (Levy and Weitz, 2009; tinyurl.com/adshuo3). Neuromarketing has surfaced as a new branch of marketing that studies the consumer's subliminal reactions to marketing material, brands, products, and product groups. It has been described as a way to apply the methods of the neurology lab to the questions of the advertising world (Wilson et al., 2008; tinyurl.com/ae05zvn).
Neuromarketing has revealed significant new information about human preferences and emotional responses by measuring the brain activation when customers view and evaluate different products or advertisements (Plassmann et al., 2012; tinyurl.com/bezoeyb).

In 2007, neuroscientists at the University of California Los Angeles scanned the brains of people watching commercials during the Super Bowl, the annual championship game in professional American football. Large advertisers paid up to $\$ 85,000$ per second to connect with viewers during the game. While people watched the advertisements, a functional magnetic resonance imaging (fMRI) machine scanned neural activity in 


\section{Neuromarketing: Understanding Customers' Subconscious Responses to Marketing} Jyrki Suomala, Lauri Palokangas, Seppo Leminen, Mika Westerlund, Jarmo Heinonen, and Jussi Numminen

areas of the brain responsible for everything from language to emotion. The results showed that, whereas a Doritos spot stimulated empathy and connection, many of the other expensive ads provoked anxiety and fear. Nationwide Insurance's ad, which featured Kevin Federline as a failed rap star stuck in a job in a fast-food restaurant, generated anxiety and feelings of insecurity that were quite opposite to the company's goals. Researchers noticed that the amygdala, which is a kind of a threat-detector region of the brain, was much more active compared to other brain regions. (Sherman, 2007; tinyurl.com/bhm2qc3)

This article uses neuromarketing to study how customer engagement is managed by salesperson behaviour and in-store marketing assets. The reason for the study is that most neuromarketing studies focus on simple product and brand preferences or reactions to advertising (Chessa and Murre, 2007; tinyurl.com/c46737m). However, marketing scholars argue that neuromarketing is still in its infancy and will likely provoke a vast amount of research that goes beyond the current emphases (cf. Lee et al., 2007; tinyurl.com/chbboqo). We argue that neuromarketing can be applied to understanding complex marketing problems, such as customer engagement processes, by showing selected marketing material to the test subjects.

We start by establishing a Virtual Customer Journey model based on the consultative selling process. The model is needed for structuring the data-collection process and for analyzing the neuroimaging data. We then describe the study, in which brain activation was measured in 16 test subjects while they participated in trials that were organized according to the phases of consultative selling. Finally, we discuss the results and implications of the study.

\section{The Need for a Virtual Customer Journey Model}

Neuromarketing is a new application of the neuroscientific approach to human behaviour in the market context. Rather than simply trying to use science to better understand the decision-making processes of individuals, neuromarketing studies test subjects' reactions to certain stimuli, which are then recorded with the aim of revealing consumer preferences. The results of these trials can potentially predict differences in thought processes being deployed by consumers that might not necessarily be observable with behaviour (Venkatraman et al., 2012; tinyurl.com/a5atyx6). The trials are aimed at building targeted advertising campaigns, designing new consumer products and shopping environments, and even determining the reasoning behind subjects' preferences for certain brands (Belden, 2008; tinyurl.com/ayfwvpb).

Previous neuromarketing studies help marketers to understand customers' emotional, cognitive, and neural activity at the moment of the purchase decision. However, the in-store shopping experience starts outside the store and continues beyond the purchase and after departing the store. The consultative selling approach suggests that marketers should understand the shopping experience from the moment the customer steps into the store until the moment they walk out, because it affects the customer-engagement process, which has long-term effects. When a customer enters a retail store, they see many different stimuli, including people, advertisements, products, and the whole marketing environment.

Marketing stimuli can be simulated and customer reaction and behaviour can be observed in the laboratory. Virtual store research (tinyurl.com/bd3gzze) is an extension of the traditional methods of marketing research. Although marketing research employs techniques such as focus groups, surveys, and observation to better understand consumer decision-making, virtual store research uses these standard research techniques within a simulated store setting. Virtual store research uses computer simulation technology to create $2 \mathrm{D}$ and $3 \mathrm{D}$ retail contexts that are deemed close to the real shopping experience. Test consumers within the virtual environment can interact with store merchandise and make purchase decisions in a way that closely resembles real, instore behaviour.

Building on this foundation, we developed a Virtual Customer Journey model based on consultative selling. The model reflects customer engagement through a step-by-step process and provides a structure for organizing marketing material required for a neuroimaging analysis. In other words, a Virtual Customer Journey model allows researchers to study customer perceptions and feelings throughout the customer-engagement process based on test subjects' perceptions of simulated events. The study constructs a Virtual Customer Journey using video clips and still pictures gathered from the high-technology sector. In the study, both marketing assets and the behaviour of salespeople are organized by the phases of consultative selling.

There are two fundamental assumptions that enable this type of a study. First, every human has mirror neur- 


\section{Neuromarketing: Understanding Customers' Subconscious Responses to Marketing Jyrki Suomala, Lauri Palokangas, Seppo Leminen, Mika Westerlund, Jarmo Heinonen, and Jussi Numminen}

ons (tinyurl.com/2d69gx) that are associated with social behaviours such as imitation and empathy. Due to the mirror neuron system, which is the neural basis of the human capacity for emotions such as empathy, the test subjects are able to associate themselves with the people and behaviour seen on the screen. Second, the activation of valuation circuitry in the forebrain during the exposure to these marketing stimuli would indicate that the test subject has an intention to buy products displayed on the screen. Valuation activation is an important precondition for test subjects' purchase decisions, and mirror neuron activation implies that they associated themselves with events taking place during the consultative sales process seen on the video.

\section{The Consultative Selling Process}

Consultative selling is the process of professionally providing information to help customers take intelligent actions to achieve their objectives (Liu and Leach, 2001; tinyurl.com/bl2apz6). It is a type of personal selling in which a salesperson plays the role of a consultant who assists the buyer in identifying customer needs and then suggesting products that satisfy those needs. Consultative selling is about finding out the prospects' needs and gaining a greater understanding of those needs. The sales professional is a valued advisor and problem-solver rather than persuader or someone merely promoting a particular product (Sharma, 2007; tinyurl.com/bzz2fdg). During the process, the salesperson needs to ensure that the customer feels satisfied with the whole purchase experience.

In addition, marketing assets - including the store environment - are often converted into a consultative selling environment to support the sales process. Typical marketing assets include an optimized product mix, branded shopping bags, and physical store components. Furthermore, displays, banners, and product information sheets support the customers' decision-making process. These assets play an important role during consultative selling, because customers are led through the path of discovery using light, motion, and visuals to strengthen the positive experience. Many high-technology companies establish flagship stores with a distinctive store location, decor, or merchandise mix to promote and attract customers. The marketing material used in this study consisted of video clips and still pictures derived from Nokia's flagship retail stores (Figure 1).

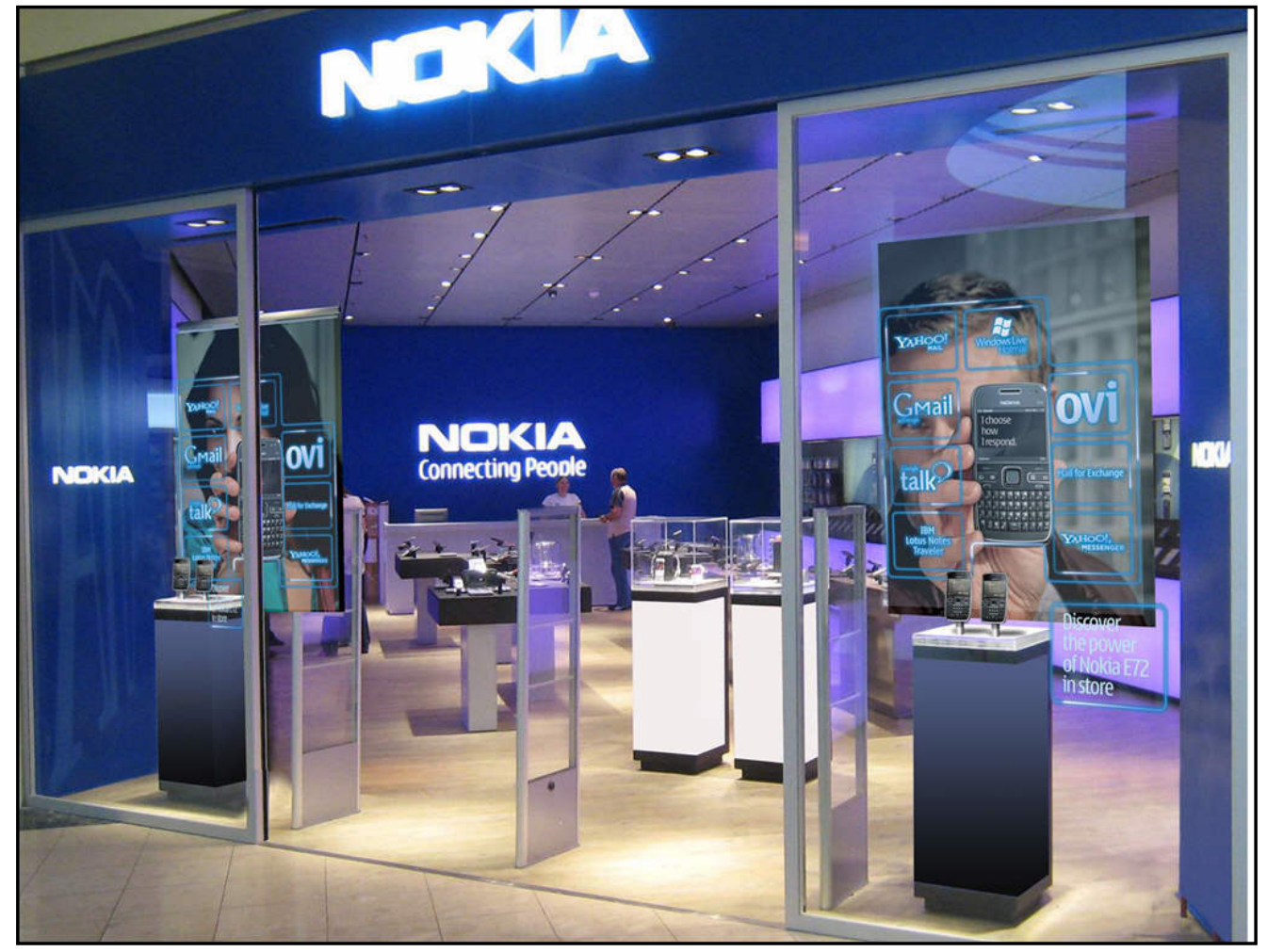

Figure 1. Nokia's flagship retail store 


\section{Neuromarketing: Understanding Customers' Subconscious Responses to Marketing} Jyrki Suomala, Lauri Palokangas, Seppo Leminen, Mika Westerlund, Jarmo Heinonen, and Jussi Numminen

Customer engagement can refer to the stages consumers travel through as they interact with a particular brand or company. This customer-engagement cycle, also known as the customer journey, has been described using a myriad of terms but most often consists of five different phases. In the context of consultative selling, we regard these phases as: i) create a connection to the customer, ii) understand customer needs, iii) address customer needs, iv) close the sale, and v) establish a sustainable customer relationship. The sales management literature suggests variations of consultative sales process and argues there is not a single model that would have become the most widely accepted process model (DeCormier and Jobber, 1993; tinyurl.com/bm9q4ba). We established the phases for the purposes of our study, and we presented and organized video and photo material in our empirical research in accordance with these phases.

The five diverse phases of consultative selling are illustrated in Figure 2 and are described below:

Phase 1: Create a connection to the customer. The purpose of the first phase is to acknowledge the presence of the customer and make them feel welcome.

Phase 2: Understand customer needs. The second phase emphasizes listening to the customer and understanding their needs, experiences, and feedback. If the salesperson does not understand customer needs adequately, the likeliness that the proposed solution will address their needs is probably not high enough to support closing the sale (Chakrabarty et al., 2010; tinyurl.com/dxslxo7).

Phase 3: Address customer needs. This phase includes determining the customer's problem, identifying a suitable solution, and proposing a solution alternative. Although the customer may have learned of the providers' product range previously, the customer often needs professional help to identify the most suitable solution for the problem, especially in the high-tech industries. An in-store demonstration of the solution should help clarify the customer's needs. As the retail salesperson performs a product demonstration, the marketing activities are concentrated on lowering the customer's purchase barrier for a particular product that is identified as a potential solution to the customer's problem (Liu and Leach, 2001; tinyurl.com/bl2apz6).

Phase 4: Close the sale. The goal of the fourth phase is to close the deal. Meeting the customer's needs and

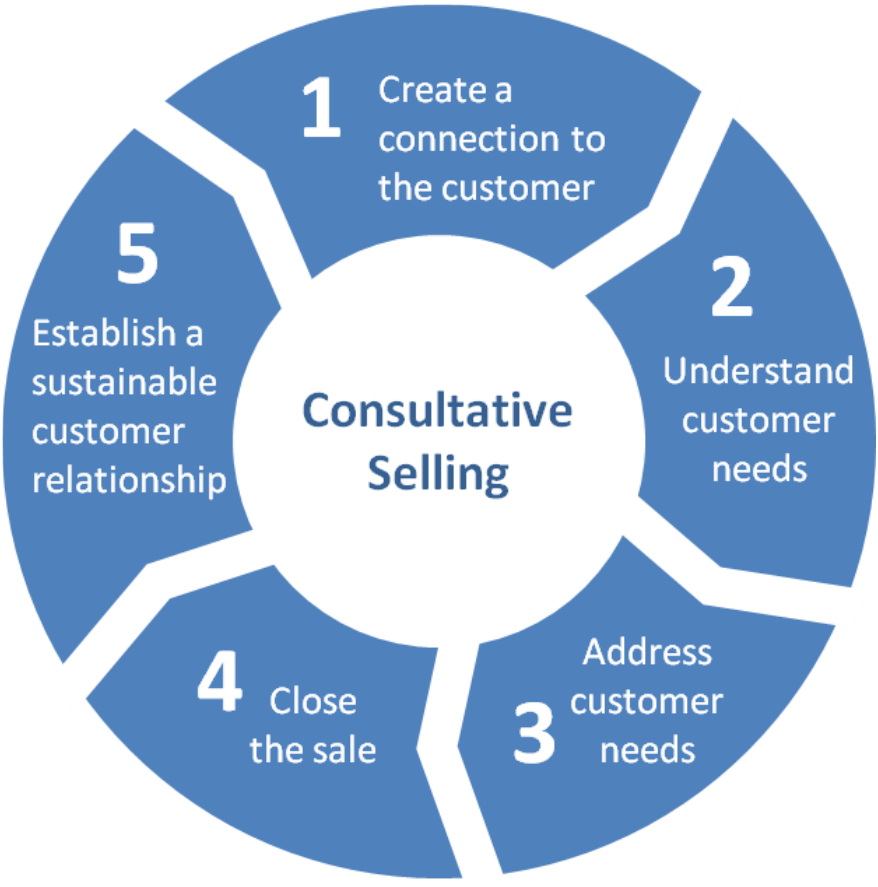

Figure 2. The five phases of consultative selling

adding value to their daily life increases the likelihood of a repeat purchase and customer loyalty. When a mutually beneficial result has been achieved, the act of closing a deal can be anticlimactic: it does not necessarily require a specific technique if the customer has already received value in the previous phases of the selling process (Moncrief and Marshall, 2005; tinyurl.com/c4kaoqt).

Phase 5: Establish a sustainable customer relationship. In the fifth phase, sellers acknowledge that the process is about building a business relationship that may later result in a repurchase (Moncrief and Marshall, 2005; tinyurl.com/c4kaoqt). Therefore, marketing focuses on ensuring that the newly founded relationship with the customer will continue after the customer walks out of the store.

\section{Research Method}

Although there are several techniques for scanning the brain, the two most important for neuromarketing are electroencephalography (EEG) and functional magnetic resonance imaging (fMRI). Whilst EEG is the recording of electrical activity outside of the brain using scale electrodes, fMRI measures changes in blood flow and oxygen levels according to mental activity and enables researchers to isolate systems of neurons associated 


\section{Neuromarketing: Understanding Customers' Subconscious Responses to Marketing Jyrki Suomala, Lauri Palokangas, Seppo Leminen, Mika Westerlund, Jarmo Heinonen, and Jussi Numminen}

with functions of the brain. The method highlights relevant networks of neurons by coloring the image of a brain in the locations of significant increases in blood flow. Using fMRI, researchers are able to image the neural activity associated with vision along with the cognitive and affective responses to stimuli (Wilson et al., 2008; tinyurl.com/aeo5zvn). Many universities use fMRI for neuroeconomics research, which uses brain-scanning technology to study how people make decisions, calculate risks and evaluate rewards, evaluate personal choices, and decide which products to buy. We used fMRI to record the brain activation of 16 test subjects at the Advanced Magnetic Imaging (AMI) Center at Aalto University (ami.aalto.fi/en/) in Finland (Figure 3).

The research process followed the suggested outline of an fMRI study for social sciences (cf. Dimona, 2012; tinyurl.com/ccqympr). The video clips shown during the trial were organized chronologically by the five phases of consultative selling. The video was presented first, and then a customer was shown six still pictures captured from the video. The test subjects' brains were scanned and brain activation data were monitored while they viewed the pictures. After each still picture, customer behaviour was evaluated by asking test subject's about their intention to purchase the product and measuring their responses on a six-point scale. Each test subject was shown 30 pictures and we stored a total of 3,240 functional magnetic image pictures per person. Therefore, the test data includes 51,840 functional brain images (16 test subjects x 3,240 images).

However, it is important to understand that the unit of analysis is not a single magnetic slice scan from a test subject's brain, but the change of the BOLD (Blood-

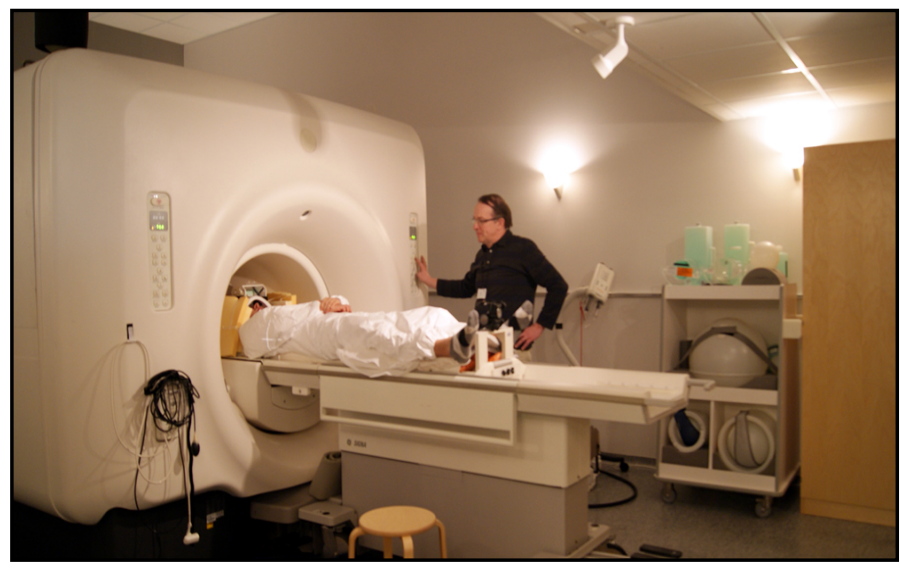

Figure 3. A test subject being prepared for fMRI at Aalto University's AMI Center
Oxygen-Level-Dependent) signal per specific time unit. All fMRI data is based on the changes of the BOLD-signal, which essentially measures the ratio of oxyhemoglobin and deoxyhemoglobin (tinyurl.com/l8uox) in the subject. The fMRI scan of each test subject's brain was performed every 1,800 milliseconds (TR), during which the image was acquired in 27 slices with a voxel size (tinyurl.com/d9ssnf) of $3 \mathrm{~mm}$ by $3 \mathrm{~mm}$. In the study, the BOLD signal analysis unit was $2 \mathrm{TR}$, equaling to a 3,600 ms interval. Figure 4 illustrates a trial protocol from a specific selling phase.

After showing the introductory video, each test subject was displayed a blank baseline. The purpose of baseline stimulus was to help the test subject to relax and to allow the BOLD signal to decrease and normalize after the expected hemodynamic response to the stimulus. After viewing a baseline, the test subjects were shown still pictures selected from the introductory video, and they were provided with a valuation stimulus in terms of a question on the test subject's willingness to purchase on scale from one to six. Each picture was shown for a duration that covered a representation of feasible actions (3.6 seconds), valuation of each action (3.6 seconds), and action selection based on the valuation (3.6 seconds) in concordance with the framework for

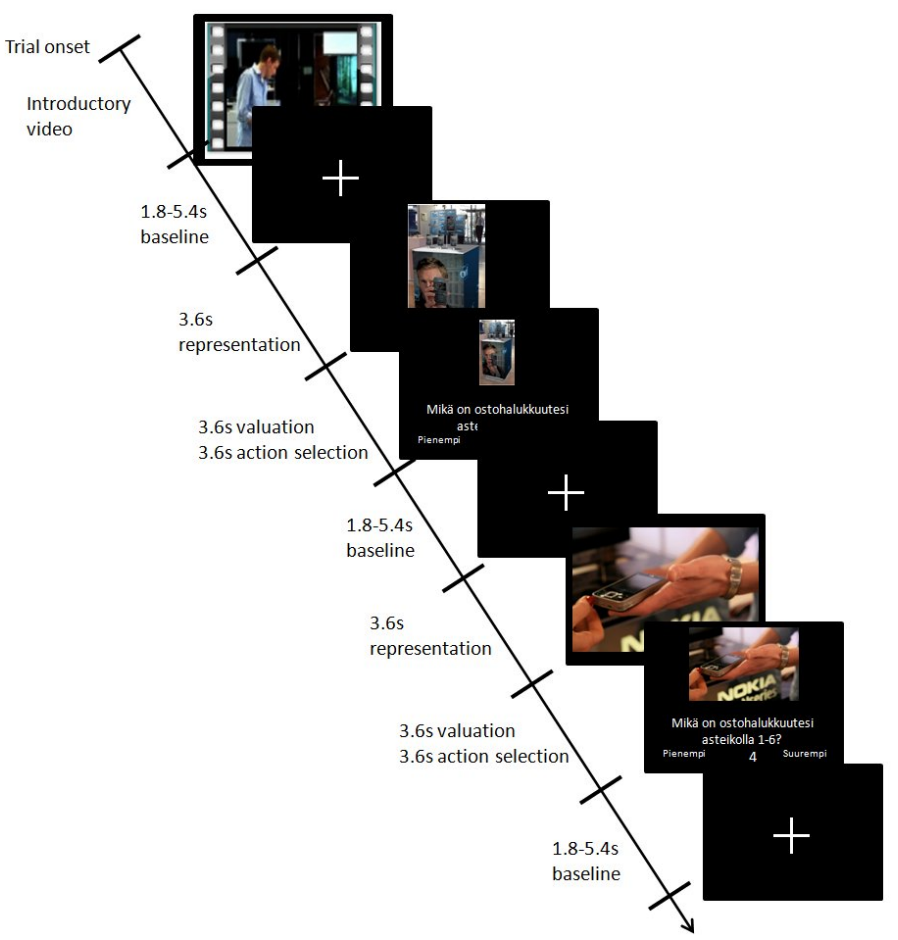

Figure 4. Example of a phase in the scan illustrating the use of video clip and still pictures 


\section{Neuromarketing: Understanding Customers' Subconscious Responses to Marketing Jyrki Suomala, Lauri Palokangas, Seppo Leminen, Mika Westerlund, Jarmo Heinonen, and Jussi Numminen}

studying the neurobiology of value-based decision making suggested by Rangel and colleagues (2008; tinyurl.com/bz57n2r). Figure 5 shows examples of the still pictures used in the trial.

\section{Steps in the Data Analysis}

Because the amount of brain data in fMRI studies is typically ample, the data analysis process is a critical step in the study. The outputs of fMRI scan events were stored as images with time stamps. The time stamps were later used to align variations in the BOLD signal with the events shown during the trial. The fMRI data was analyzed in three steps: i) preprocessing, ii) formulating a design matrix, and iii) performing statistical tests. These steps are described below:

Step 1: Preprocessing. Each test subject's brain data were preprocessed, which means that the collected data were corrected and organized to be comparable with the rest of the data from the same test subject. First, the movement of the subject during the scan was corrected. The natural movement of the brain causes displacement of several millimeters, which can be corrected by alignment. Second, a process of co-registration enabled a positioning of BOLD signal on the anatomical image of the test subject. The images had to be further processed to apply temporal and spatial comparison of data between the test subjects. Third, after a normalization process, test subjects' functionally homogenous brain sections became spatially comparable and it was possible to use standard coordinates to refer to one part of a brain among the test subjects. Fourth, a spatial smoothing with a Gaussian kernel was applied to the data in the study to increase the signal-to-noise ratio and the validity of inferences in the analysis (Henriksson, 2009; tinyurl.com/bzq9glo). With preprocessing, it was possible to apply within-subject and between-subject statistical analyses for the neurophysiological data.

Step 2: Formulation of a design matrix. The expected intensity of brain activity (BOLD signal) was modeled to a design matrix (Friston, 2004; tinyurl.com/bjm82vw). The design matrix is a specific table, where rows represent points in time and columns represent test variables. The matrix serves as a template for further statistical analyses. In this study, each of the columns in the design matrix depicts one of the five phases in the consultative selling process, as illustrated in Figure 2.

Step 3: Performing statistical tests. The analysis of the data was performed by applying a statistical test on
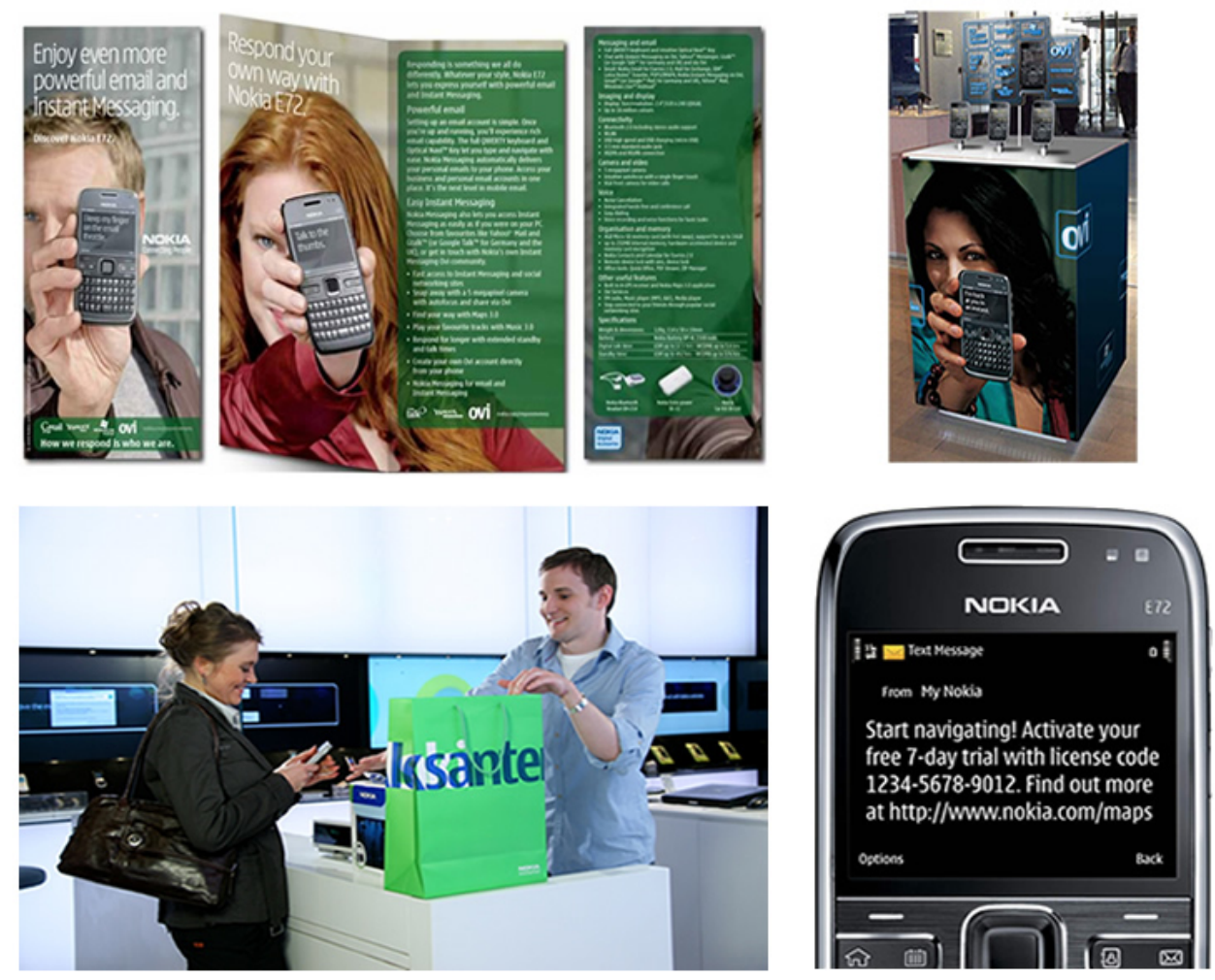

Figure 5. Examples of still pictures from the video shown to test subjects during the trial 


\section{Neuromarketing: Understanding Customers' Subconscious Responses to Marketing Jyrki Suomala, Lauri Palokangas, Seppo Leminen, Mika Westerlund, Jarmo Heinonen, and Jussi Numminen}

each voxel. First, the statistical parametric maps of individual test subjects were analysed using a t-test with respective t-contrasts. The results were modelled into the statistical parametric map based on the common anatomical brain image. Secondly, the group analysis was performed for the statistical parametric maps including the results of the t-tests from the individual analyses. With this approach, it was possible to test the assumption that particular differences between conditions account for the variance in physiology. This study applied the method to analyze the differences in neurophysiological responses between the phases of consultative selling. The between-subject analysis was performed by using one-way t-test. This test compared the statistical parametric maps of individual test subjects in order to drive inferences in the group level. The between-subject analysis was used to test which brain areas are active during a specific consultative selling phase. The results were counted as mean brain activation of the group.

\section{Results of the Analysis}

Different components of the brain's valuation circuits were active at each phase of the Virtual Customer Journey. First, dorsolateral prefrontal cortex (DLPFC) activation was found at each five phases of the consultative selling process. DLPFC is an area in the primate brain that serves as the highest cortical area responsible for motor planning, organization, and regulation. It plays an important role in the integration of sensory and mnemonic information and the regulation of intellectual function and action, and it is involved in working memory. Figure 6 shows the brain activation of DLPFC
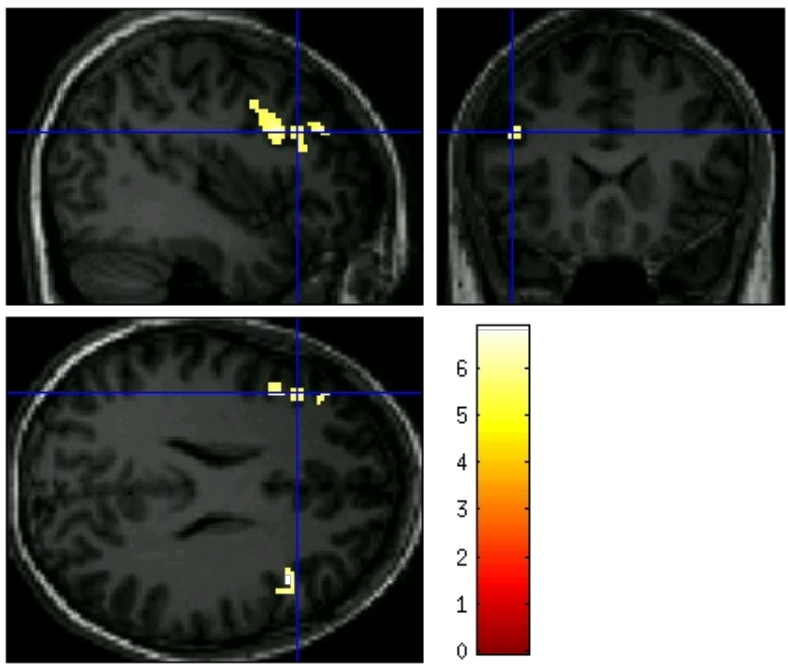

Figure 6. Brain activation of the dorsolateral prefrontal cortex (DLPFC) (above left: sagittal view, above right: coronal view, and below: axial view of the brain).

The test subjects' fMRI showed significant correlation to the consultative selling process in DLPFC. The Family Wise Error (FWE) correction was applied to the intersubject analysis to address the variance in the location of the neural activity. The statistical threshold was set at $\mathrm{p}<0.05$ voxel level (FWE-corrected) and only clusters with at least 10 activated voxels were reported. DLPFC activation indicates that the Virtual Customer Journey organized by the phases of consultative selling activates the general valuation system of the brain. Previous research shows that this activation is an important prerequisite for purchase decisions (Glimcher, 2010; tinyurl.com/37mnmow). DLPFC activation tends to increase when a familiar brand is shown (McClure et al., 2004; tinyurl.com/cyvpt6l) and when customers intend to buy the products displayed on the screen (Plassmann et al., 2007; tinyurl.com/d3lqkdt).

Second, the inferior frontal gyrus (IFG) was active during most phases of the consultative selling process. The test subjects showed significant correlation with phases $1,2,3$ and 5 in IFG; the threshold was set at $\mathrm{p}<0.05$ voxel level (FWE-corrected) with a minimum cluster size of 10 voxels. Figure 7 illustrates the activation of the IFG (above left: sagittal view, above right: coronal view, and below: axial view of the brains).

Previous studies suggest that response in the IFG acts as a safety signal, because it shows a higher response to safer options than unsafe option (Christopoulos et al., 2009; tinyurl.com/ac4t6am). Therefore, the IFG activation
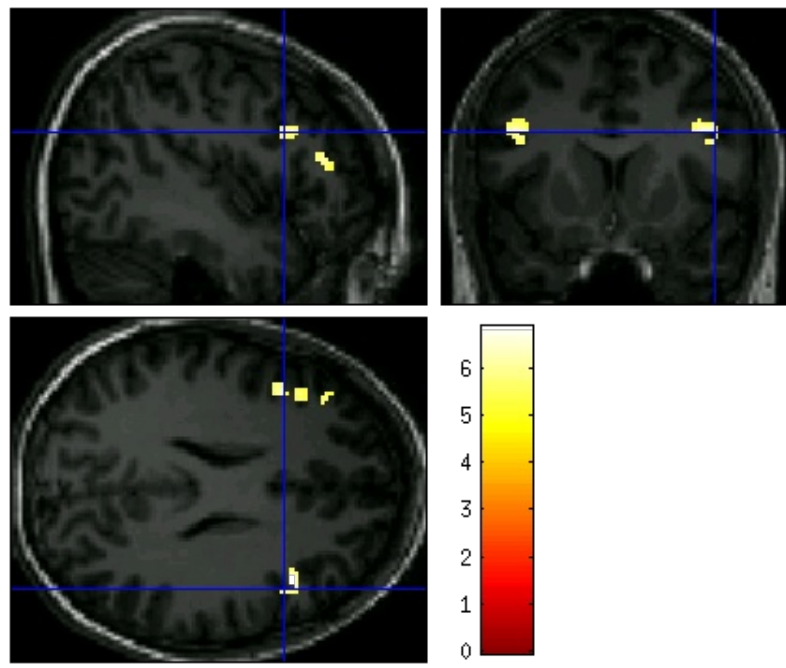

Figure 7. Activation of the inferior frontal gyrus (IFG) 


\section{Neuromarketing: Understanding Customers' Subconscious Responses to Marketing Jyrki Suomala, Lauri Palokangas, Seppo Leminen, Mika Westerlund, Jarmo Heinonen, and Jussi Numminen}

in our trials indicates that test subjects perceived the shopping environment as safe, and they did not feel fear or risk. The IFG activation was absent only in phase 4 (closing the sale); however, the activation increased again in the final phase. It has been shown that the IFG is active when an individual performs an action or sees another person performing an action (Iacoboni and Dapretto, 2006; tinyurl.com/c8hckl3). Therefore, the IFG activation in our trials shows test subjects were not only seeing the people on the screen but also associating themselves with those people and mirroring their behaviour and feelings during the consultative selling process (Keysers and Gazzola, 2006; tinyurl.com/bwkwv3s). This finding supports the idea that, by using an artificial environment (i.e., by creating virtual reality in the laboratory), it is possible to establish a realistic shopping environment where customers can participate in the buying process displayed on the screen.

Finally, hippocampus activation was found at phases 1 and 2, as well as 4 and 5 , during the consultative selling process; the threshold was set $\mathrm{p}<0.05$ (FWE) at voxel level and a minimum cluster size of 10 voxels. Hippocampus activation indicates that the test subject's memory was active during the process. The activation of the memory system was expected, because the information shown during the process likely triggers an individual's memories. Figure 8 shows the hippocampus activation (above left: the sagittal view, above right: coronal view, and below left: axial view of the brain).
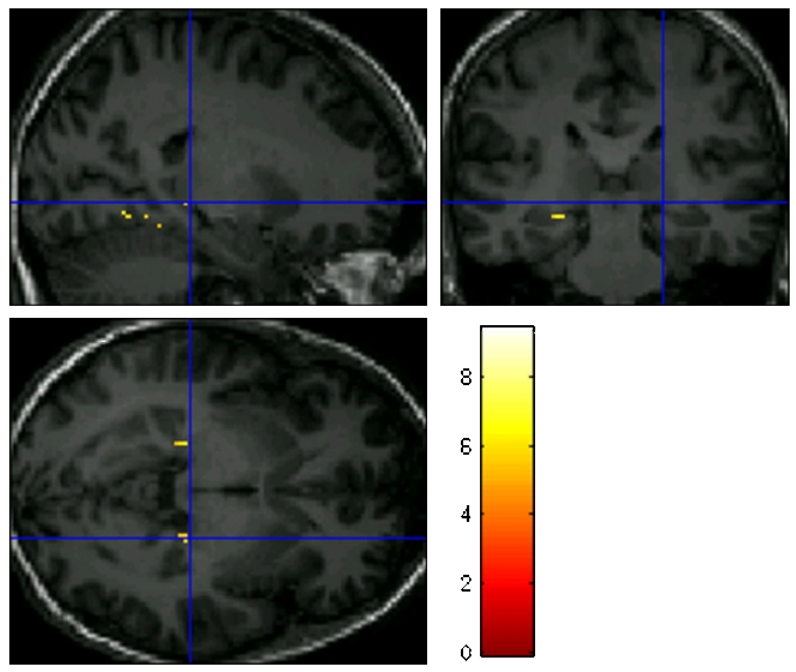

Figure 8. Hippocampus activation

\section{Conclusion}

This article showed that neuroimaging is a suitable method for investigating consumer perceptions in situations where pleasure and displeasure can be measured at each step of the customer engagement. For the purpose of the study, we established a Virtual Customer Journey model, which is based on the consultative selling process and is easy to apply in neuromarketing research laboratories. It is useful for neuromarketing research that goes beyond traditional market research and customer satisfaction surveys. The level of satisfaction at each moment of the shopping experience is more important than the emphasis on products. Because the brain's valuation system acts at a conscious level, the information required for analysis is unachievable without the help of neuroimaging. That is, customer preferences are subconscious and difficult to express using words (Berns and Moore, 2012; tinyurl.com/czd4vkr).

Perceived risk is an important factor affecting customers' decision-making processes. However, our analysis could not explain possible fluctuation in perceived risk during the process. The perception of risk among test subjects remained at a low level at each step of the process, meaning that the customer felt safe throughout the buying process. The perceived level of safety only had a marginal drop at the moment of the purchase decision (phase 4). However, the brand used in our trial may indicate a limitation to the study, because Nokia's strong brand in Finland can endorse the feelings of safety and affect neural mechanisms of decision making (cf. Schaefer and Rotte, 2007; tinyurl.com/bplx4q6). Nevertheless, different stages in the buying process were perceived quite similarly, indicating that customers felt comfortable about the consultative selling and purchasing was perceived as easy throughout the process. This finding suggests that consultative selling is an effective way to serve customers and their needs, especially in high-technology markets, and that it reflects a step-by-step customer engagement starting from the moment the customer enters into the retail store and ending only after closing the deal and ensuring the initiation of a longstanding customer relationship.

The analysis showed that important areas in the brain were active during the buying process. These areas included the dorsolateral prefrontal cortex (DLPFC), in which the activity equates to increased feelings of 


\section{Neuromarketing: Understanding Customers' Subconscious Responses to Marketing} Jyrki Suomala, Lauri Palokangas, Seppo Leminen, Mika Westerlund, Jarmo Heinonen, and Jussi Numminen

safety, thereby having a positive effect on the individual's willingness to buy. Given that neuroimaging reveals brain activity, it can help marketers to identify and reduce negative feelings such as fear, insecurity, danger, and risk among customers, and thus promote customers' willingness to buy. The benefit of neuroimaging is that even a relatively small group of test subjects can provide reliable information on customer reactions to marketing stimuli (Berns and Moore, 2012; tinyurl.com/czd4vkr). The information is especially useful for companies building customer-appealing stores and shopping environments, as well as for planning their sales processes and producing marketing material such as advertisements that support the company's positive image and foster sales.

To sum up, neuromarketing cannot push a "buy button" in the customer's brain because there is no "buy button" to push. However, activation in the inferior frontal gyrus (IFG), which is a part of the mirror neuron system, suggests that test subjects associate themselves with objects (including people) seen on video during the simulated customer journey. The findings indicate that they tend to think "the person on the screen is me", and they behave, react, and feel accordingly. This notion encourages the use of neuromarketing that utilizes still pictures and video clips as well as arbitrarily chosen small groups of test subjects for studying customer behaviour and reactions in different situations. The study also provides suggestions for future research topics in neuromarketing. We believe that the findings and the method can be used not only for assessing the buying process, but also for testing new product and service concepts and applications, especially in the high-tech sector.

\section{Acknowledgements}

Marketing images are reprinted by courtesy of Nokia.

\section{About the Authors}

Jyrki Suomala, Ph.D. (Education), holds positions as Principal Lecturer at the Laurea University of Applied Sciences and Adjunct Professor in the University of Oulu in Finland. Jyrki holds a doctoral degree in Education from the University of Jyväskylä, Finland. His research and consultation interests include the neurophysiological basis of human behaviour in marketing and education. Jyrki is the founder and head of the Neuroeconomics Lab at the Laurea University of Applied Sciences. He has been a visiting researcher at the University of California, Santa Barbara, for a period of three years.

Lauri Palokangas, BBA, graduated from Finland's Laurea University of Applied Science's Business Management Programme in summer 2010 while continuing his career at Nokia. His work is mainly related to smartphones and he has gained significant experience through various information technology, pre-sales, and marketing positions over more than a decade. Lauri's thesis work focused on measuring the impact of retail marketing assets on a customer's purchase decision during the solution-selling process. The hypotheses of the research are from the discipline of neuroeconomics, whereas the behavioural research relates to Lauri's areas of expertise at Nokia. The thesis was recognized in a 2010 Thesis of the Year competition.

Seppo Leminen, D. Sc. (Econ.), Lic. Tech., holds positions as Principal Lecturer at the Laurea University of Applied Sciences and Adjunct Professor in the Aalto University School of Business in Finland. Seppo holds a doctoral degree in Marketing from the Hanken School of Economics and a licentiate degree in Information Technology at the Helsinki University of Technology. His research and consultation interests include value co-creation and capture with users as well as relationships, services, and business models in marketing. He runs various living lab and business model projects relating to ICT.

Continued on next page... 


\section{Neuromarketing: Understanding Customers' Subconscious Responses to Marketing} Jyrki Suomala, Lauri Palokangas, Seppo Leminen, Mika Westerlund, Jarmo Heinonen, and Jussi Numminen

\section{About the Authors (continued)}

Mika Westerlund, D. Sc. (Econ.) is an Assistant Professor at Carleton University's Sprott School of Business in Ottawa, Canada. He previously held positions as a Postdoctoral Scholar in the Haas School of Business at the University of California Berkeley and in the School of Economics at Aalto University in Finland. Mika earned his doctoral degree in Marketing from the Helsinki School of Economics. His doctoral research focused on software firms' business models and his current research interests include open innovation, business strategy, and management models in high-tech and serviceintensive industries.

Jarmo E. A. Heinonen, $\mathrm{PhD}$ (Education), Lic.Sc (Marketing), M.Sc. (Food Economy) holds a position as Principal Lecturer at the Laurea University of Applied Sciences, Finland. He has also studied marketing and business administration at the University of Rhode Island and the University of California Davis in the United States. Jarmo holds a doctoral degree in Education from the University of Tampere, Finland, and a licentiate degree in marketing with a food science emphasis at the University of Helsinki. Previously, he was Director at Palmenia Centre for Continuing Education at the University of Helsinki. He has authored books, research, and articles on research methods, marketing research, neuromarketing, and neuroeconomics.

Jussi Numminen, MD, Ph.D., holds a position as fMRI physician at Helsinki Medical Imaging Center, Töölö Hospital, University of Helsinki. Dr. Numminen has broad experience in functional neuroimaging research and is the author of several publications in international peer-refereed journals such as PNAS, Human Brain Mapping, and Frontiers in Neuroscience. He has a strong theoretical background in neuroimaging methodology and data analysis. In addition, he has extensive experience of the clinical use of fMRI in pre-surgical evaluation of patients with brain tumours.

Citation: Suomala, J., L. Palokangas, S. Leminen, M.

Westerlund, J. Heinonen, and J. Numminen. 2012.

(cc) BY

Neuromarketing: Understanding Customers

Subconscious Responses to Marketing. Technology

Innovation Management Review. December 2012: 12-21. 